\title{
TCR $\beta$ spectratyping in RA: evidence of clonal expansions in peripheral blood lymphocytes
}

\author{
F C Hall, K Thomson, J Procter, A J McMichael, B P Wordsworth
}

\begin{abstract}
Objective-To compare the TCR $\beta$ repertoire of peripheral blood CD8 enriched (CD8+) and depleted (CD8-) $T$ cells in rheumatoid arthritis (RA) patients and controls using CDR3 length analysis (spectratyping).

Methods-CD8+ and CD8- T cells were separated from 14 RA patients and 12 controls, using magnetic beads coated with anti-CD8 monoclonal antibodies. cDNA was prepared as the template for amplification with $22 \mathrm{~V} \beta-\mathrm{C} \beta$ primer pairs. The products were resolved by electrophoresis in an ABI373 sequencer using GENESCAN software. Expansions were identified as dominant CDR3 lengths, where the area underlying the corresponding peak exceeded the sum of the areas of the two adjacent peaks. This method was validated by sequencing 10 samples displaying dominant peaks. The expansion frequencies in RA patients and controls were compared using the $\chi^{2}$ test statistic.

Results-Dominant peaks were evident in several V $\beta$ families. They were more frequent in RA patients in both the CD8+ subset (RA normalised frequency 10.6; control normalised frequency $8.0 ; p=0.03$ ) and the CD8- subset (RA normalised frequency 2.9; control normalised frequency $1.5 ; p=0.02$ ). Sequencing of 10 samples exhibiting dominant peaks revealed an unequivocal clonal expansion in nine (90\%).

Conclusions-RA patients exhibited a significantly increased frequency of $T$ cell expansions both in the CD8+ and CD8subsets. This phenomenon may reflect the proliferation of autoreactive cells, a nonspecific expansion of memory $T$ cells in response to pro-inflammatory cytokines or a defect of $T$ cell regulation that predates the onset of RA and may itself predipose to disease.

(Ann Rheum Dis 1998;57:319-322)
\end{abstract}

A pivotal role of $T$ cells in the initiation of rheumatoid arthritis (RA) has been inferred from the prominence of CD4+ $\mathrm{T}$ cells in the synovium early in disease, the association of RA with particular HLA-DR4 and DR1 antigens, the efficacy of treatments that deplete or suppress CD4+ cells, and animal models of chronic arthritis. The $\mathrm{T}$ cell receptor (TCR) endows this cell with its discriminatory properties. In developing $\mathrm{T}$ cells, functional genes for the $\alpha$ and $\beta$ chains of the TCR chain are produced by rearranging selected $\mathrm{V} \alpha / \mathrm{J} \alpha$ or
$V \beta / D \beta / J \beta$ segments and joining them to their respective constant regions. Unlike the CDR1 and CDR2 loops, which are encoded in the germline, the CDR3 loops are determined by the $\mathrm{V} \alpha \mathrm{J} \alpha$ or $\mathrm{V} \beta \mathrm{D} \beta \mathrm{J} \beta$ junctional region and diversity is further enhanced by trimming the germline segments and insertion of nongermline encoded nucleotides. The resulting variation in length of the CDR3 $\beta$ loop is the basis for the "spectratyping" technique, in which the CDR3 $\beta$ region is amplified and the distribution of CDR3 $\beta$ lengths can be used as a readout of TCR $\beta$ repertoire.

It is widely believed that $\mathrm{T}$ cells initiate a pathogenic immune response in RA by specific recognition of antigen locally in the joint, leading to synovitis, pannus formation, and joint damage. Although no consistent TCR motif has emerged in RA patients, ${ }^{1}$ repertoire studies using monoclonal antibodies and CDR3 length analyses have identified abnormal patterns of CD4+ clonal expansion in both peripheral blood and synovial $\mathrm{T}$ cell populations. ${ }^{23} \mathrm{CD} 8+$ $\mathrm{T}$ cells are less strongly implicated in RA but expansions of a CD8+ large granular lymphocyte population occur in approximately $33 \%$ of cases of Felty's syndrome. ${ }^{4}$ Their role is unclear but MHC restricted anti-viral activity, antibody dependent cell mediated cytotoxicity, and suppressor activity have been suggested. CD8+ expansions have also been described in RA by spectratyping ${ }^{5}$ and using anti-TCR monoclonal antibodies. ${ }^{6}$

In this study, TCR $\beta$ spectratyping was used to compare the repertoire of $22 \mathrm{~V} \beta$ families in both the CD8+ and CD8- subsets of peripheral blood lymphocytes in 14 RA patients and 12 controls. The number of CDR3 lengths per $\mathrm{V} \beta$ family was determined as an overall measure of repertoire complexity and the frequencies of CD8+ and CD8- expansions in each V $\beta$ family were compared between RA and controls.

\section{Methods}

Fourteen unrelated RA patients ( 11 female, 3 male), who fulfilled the ACR revised criteria, ${ }^{7}$ were recruited from a rheumatology outpatient department. Twelve controls (9 female, 3 male) were recruited from hospital staff. All were white British subjects. The mean (SD) age of patients was 54 (13), whereas, for controls, it was 42 (16). Table 1 shows the demographic characteristics, HLA-DR type, and rheumatoid factor status of subjects.

Peripheral blood mononuclear cells (PBMC) were separated from peripheral venous blood by Ficoll-Hypaque gradient centrifugation (Lymphoprep, Birmingham, UK).
Accepted for publication 4 March 1998 
Table 1 Demographic characteristics and HLA-DR types of $R A$ patients and controls

\begin{tabular}{|c|c|c|c|c|c|}
\hline & Sex & Age & $D R B 1$ & & $R F$ \\
\hline C1 & $\mathrm{F}$ & 24 & ${ }^{\star} 03$ & ${ }^{\star} 11$ & ND \\
\hline $\mathrm{C} 2$ & $\mathrm{~F}$ & 28 & ${ }^{\star} 09$ & ${ }^{\star} 14$ & ND \\
\hline C3 & $\mathrm{F}$ & 30 & ${ }^{\star} 0401$ & $\star 15$ & ND \\
\hline C4 & $\mathrm{F}$ & 31 & ${ }^{\star} 07$ & $\star 15$ & ND \\
\hline C5 & M & 31 & ${ }^{\star} 01$ & $\star 14$ & ND \\
\hline C6 & M & 32 & ${ }^{\star} 01$ & ${ }^{\star} 09$ & ND \\
\hline C7 & $\mathrm{F}$ & 38 & $\star^{\star} 03$ & $\star 13$ & ND \\
\hline C8 & M & 53 & ${ }^{\star} 0401$ & ${ }^{\star} 0405$ & ND \\
\hline C9 & $\mathrm{F}$ & 54 & ${ }^{\star} 12$ & ${ }^{\star} 15$ & ND \\
\hline $\mathrm{C} 10$ & $\mathrm{~F}$ & 58 & ${ }^{\star} 07$ & $\star 12$ & ND \\
\hline C11 & $\mathrm{F}$ & 56 & ${ }^{\star} 13$ & ${ }^{\star} 13$ & ND \\
\hline C12 & $\mathrm{F}$ & 73 & ${ }^{\star} 03$ & $\star 11$ & ND \\
\hline R1 & $\mathrm{F}$ & 37 & ${ }^{\star} 0401$ & ${ }^{\star} 0401$ & $\mathrm{Y}$ \\
\hline $\mathrm{R} 2$ & $\mathrm{~F}$ & 40 & $\star_{0401}$ & ${ }^{\star} 0404$ & $\mathrm{Y}$ \\
\hline R3 & $\mathrm{F}$ & 41 & ${ }^{\star} 0401$ & ${ }^{\star} 07$ & $\mathrm{Y}$ \\
\hline $\mathrm{R} 4$ & M & 42 & ${ }^{\star} 07$ & $\star 13$ & $\mathrm{~N}$ \\
\hline R5 & $\mathrm{F}$ & 43 & ${ }^{\star} 0408$ & ${ }^{\star} 0101$ & $\mathrm{Y}$ \\
\hline R6 & $\mathrm{F}$ & 56 & ${ }^{\star} 0401$ & ${ }^{\star} 0401$ & $\mathrm{Y}$ \\
\hline $\mathrm{R} 7$ & $\mathrm{~F}$ & 61 & ${ }^{\star} 0101$ & $\star 13$ & $\mathrm{Y}$ \\
\hline R8 & $\mathrm{F}$ & 61 & ${ }^{\star} 13$ & ${ }^{\star} 16$ & $\mathrm{Y}$ \\
\hline R9 & $\mathrm{F}$ & 63 & $\star_{0405}$ & ${ }^{\star} 10$ & $\mathrm{Y}$ \\
\hline R10 & $\mathrm{F}$ & 63 & ${ }^{\star} 0401$ & $\star 11$ & $\mathrm{Y}$ \\
\hline R11 & M & 63 & ${ }^{\star} 0401$ & ${ }^{\star} 0101$ & $\mathrm{Y}$ \\
\hline $\mathrm{R} 12$ & $\mathrm{~F}$ & 66 & $\star^{\star} 0401$ & ${ }^{\star} 11$ & $\mathrm{Y}$ \\
\hline R13 & $\mathrm{F}$ & 72 & ${ }^{\star} 0404$ & $\star 0701$ & $\mathrm{Y}$ \\
\hline R14 & M & 75 & ${ }^{\star} 11$ & ${ }^{\star} 14$ & $\mathrm{~N}$ \\
\hline
\end{tabular}

HLA-DRB1 genotypes (including HLA-DR4 subtypes) are shown for all controls (C1-12) and all patients with RA (R1-R14). The presence or absence of rheumatoid factor (RF) is indicated for all RA patients (ND indicates test not done in controls).

A three hour stimulation of PBMC with 1 $\mu \mathrm{g} / \mathrm{ml}$ phytohaemagglutinin (PHA) in $\alpha$ modified Eagle's medium supplemented with $5 \%$ $\mathrm{AB}$ human serum was performed to increase the yield of mRNA from $\mathrm{T}$ cells. The CD8+ and CD8 $-\mathrm{T}$ cell subsets were separated using magnetic beads coated with anti-CD8 monoclonal antibodies (Dynal, Oslo, Norway), and the extent of separation was assessed by fluorescence analysis on a Becton-Dickinson FACScan with Cellquest software, using phycoerythrin labelled anti-CD4 and fluoroscein isothiocyanate labelled anti-CD8 monoclonal antibodies (Sigma, Poole, UK). Total RNA was prepared from aliquots of $1-5 \times 10^{6} \mathrm{CD} 8+$ or CD8- mononuclear cells using the RNAzolB method (Biotecx, Houston, TX, USA). RNA

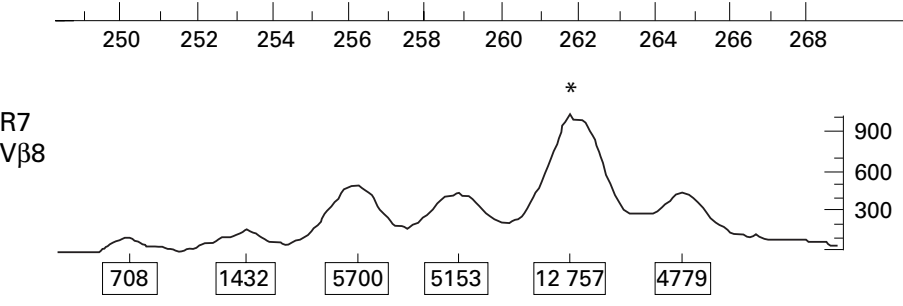

$\begin{array}{llllllllllllll}220 & 222 & 224 & 226 & 228 & 230 & 232 & 234 & 236 & 238 & 240 & 242 & 244 & 246\end{array}$

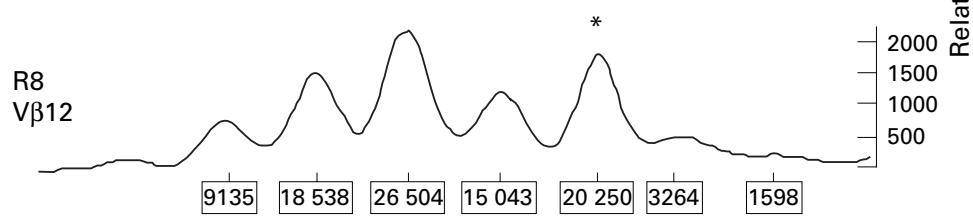

Figure 1 Dominant CDR3 lengths are indicated ( $*$ ) against a background Gaussian distribution of CDR3 length distribution. Each peak in the spectratype is annotated with the area underlying the curve. The $y$ axis represents relative units of fluorescence calculated by the Genescan software. The $x$ axis indicates the length of PCR product (bp). concentration was assessed by optical density and first-strand cDNA synthesis was performed on $5 \mu \mathrm{g}$ aliquots of RNA using $0.1 \mathrm{U}$ oligo(dT) $)_{12-18}$ primer (Pharmacia, Uppsala, Sweden) and AMV reverse transcriptase (Promega, Madison, WI, USA).

The cDNA from $14 \mathrm{RA}$ patients and 12 controls was used as template for $22 \mathrm{~V} \beta-\mathrm{C} \beta$ amplifications, which were performed in 96 well plates (Costar, High Wycombe, UK). The primer sequences were modified from the set used by Gregersen and coworkers. ${ }^{8}$ The V $\beta 10$ and V $\beta 19$ primers were excluded, because these BV segments are transcribed pseudogenes. ${ }^{9}$ The V $\beta 22$ primer described in the Gregersen set is a perfect match for BV23 rather than BV22 and is renamed as the VB23 primer in this study. A $10 \mu \mathrm{l}$ reaction volume contained $1 \mu \mathrm{cDNA}, 3 \mathrm{pmol}$ of fluorescently labelled $\mathrm{V} \beta$ primer, 2 pmol $\mathrm{C} \beta \mathrm{R}, 16 \mathrm{mM}$ ammonium sulphate, $67 \mathrm{mM}$ TRIS- $\mathrm{HCl}(\mathrm{pH}$ 8.8), $0.1 \%$ TWEEN-20, $0.2 \mathrm{mM}$ dNTPs, 0.5 $\mathrm{mM}$ magnesium chloride, and 1.25 units of Taq polymerase (Bioline, London, UK). Omnigene thermocyclers (Hybaid, Teddington, UK) were programmed to provide 35 amplification cycles of $94^{\circ} \mathrm{C}$ for one minute, $55^{\circ} \mathrm{C}$ for one minute, $72^{\circ} \mathrm{C}$ for 45 seconds. The amplification products were separated by electrophoresis on 6\% acrylamide gels (Severn Biotech Ltd, Kidderminster, UK) each run at a constant $1000 \mathrm{~V}$ in ABI373 sequencers (Applied Biosystems, Warrington, UK) and the gels were collected and analysed using GENESCAN software. ${ }^{10}$

The GENESCAN GENOTYPER package was programmed to label the 10 highest peaks in each spectratype with the peak area. An expansion was defined as a peak with an area exceeding the sum of the areas of the two adjacent peaks. In cases where an apparently dominant peak was adjacent to a gap in the spectratype, or lay at the edge of the spectratype, an expansion was defined as a peak with an area at least twice that of the single adjacent peak. The frequency of expansions was expressed as the normalised expansion frequency relative to the proportion of successful V-C amplifications in an indivdual subject. Comparative statistics were performed using the $\chi^{2}$ test statistic.

Twelve amplification products (10 containing expansions; two without expansions) were subcloned into the pMosBlue T vector (Amersham International, Amersham, UK) and sequenced using the USB sequencing kit (United States Biochemical Corp, Cleveland, Ohio). The CDR3 loop boundaries were defined by the the conserved amino acid motif, CAS, encoded by the BV gene segment, and the FGXG motif encoded by the BJ gene segment.

\section{Results}

The majority of $\mathrm{V} \beta-\mathrm{C} \beta$ spectratypes consisted of between four and nine peaks representing CDR3 lengths differing by increments of three base pairs. The mean (SD) number of CDR3 lengths per spectratype was 6.0 (1.2) in RA patients and $6.5(1.2)$ in controls (NS). In comparison with PBMC, which contained an 


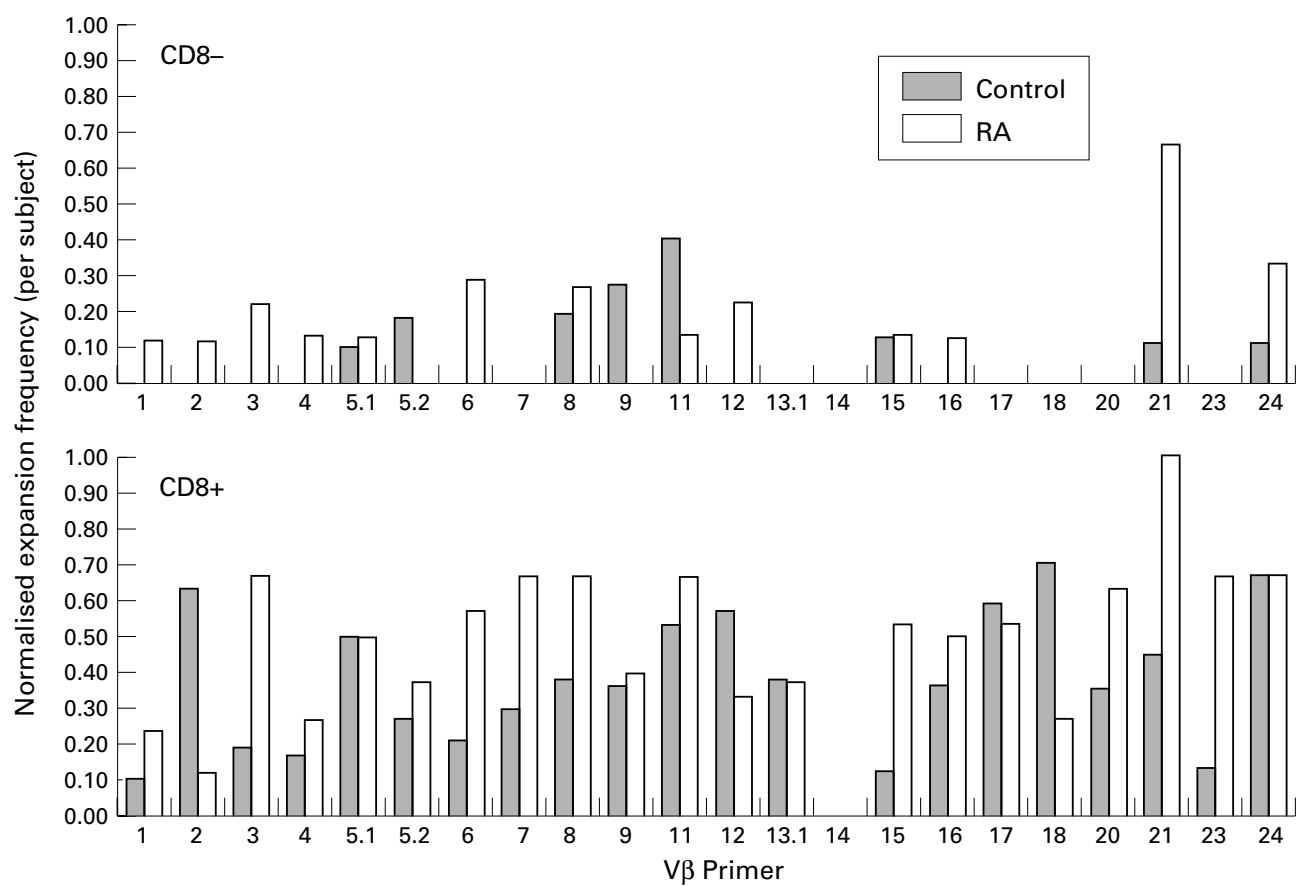

Figure 2 The frequency of expansions in CD8- and CD8+ subsets of peripheral blood $T$ cells are indicated in both $R A$ patients and controls. Frequencies are normalised according to the proportion of successful V $\beta-C \beta$ amplifications in a given person.

Table 2 Sequence data from 10 dominant peaks identifed in $R A$ patients

\begin{tabular}{|c|c|c|c|c|c|c|c|}
\hline Patient & DRB1 genotype & Expansion & Subset & $\begin{array}{l}\text { Number } \\
\text { sequenced }\end{array}$ & $\begin{array}{l}\text { Number } \\
\text { clonal }\end{array}$ & $C D R 3$ & $\begin{array}{l}\text { Bf } \\
\text { segment }\end{array}$ \\
\hline $\mathrm{R} 1$ & $\star 13 / \star 16$ & $\mathrm{~V} \beta 1$ & CD4+ & 13 & 7 & CAS TPGVKMNTEAF FGQG & $1 \mathrm{~S} 1$ \\
\hline $\mathrm{R} 4$ & ${ }^{\star} 0401 /{ }^{\star} 0404$ & $\mathrm{~V} \beta 8$ & CD4+ & 21 & 10 & CAS GMTGQGTDTQY FGPG & $2 \mathrm{~S} 3$ \\
\hline $\mathrm{R} 2$ & ${ }^{\star} 0408 /{ }^{\star} 0101$ & $\mathrm{~V} \beta 11$ & CD8+ & 10 & 6 & CAS VWTTHEF FGPG & $2 \mathrm{~S} 1$ \\
\hline R3 & ${ }^{\star} 0401 /{ }^{\star} 0401$ & $V \beta 5.1$ & CD8+ & 9 & 8 & CAS SWDKAYEQY FGPG & $2 \mathrm{~S} 7$ \\
\hline R3 & ${ }^{\star} 0401 /{ }^{\star} 0401$ & $V \beta 5.2$ & CD8+ & 16 & 2 & & \\
\hline $\mathrm{R} 4$ & $\star 0401 / \star 0404$ & $V \beta 5.2$ & CD8+ & 12 & 6 & CAS SLIDSILTDTQY FGPG & $2 \mathrm{~S} 3$ \\
\hline $\mathrm{R} 4$ & ${ }^{\star} 0401 /{ }^{\star} 0404$ & $\mathrm{~V} \beta 18$ & CD8+ & 20 & 9 & CAS SPSRQISGANVLT FGAG & $2 S 6$ \\
\hline R5 & ${ }^{\star} 0401 /{ }^{\star} 11$ & $\mathrm{~V} \beta 11$ & CD8+ & 12 & 4 & CAS SFSRSTDTQY FGPG & $2 \mathrm{~S} 3$ \\
\hline R5 & ${ }^{\star} 0401 /{ }^{\star} 11$ & $\mathrm{~V} \beta 13.1$ & CD8+ & 17 & 9 & CAS SQGRTSVTEQY FGPG & $2 S 7$ \\
\hline R6 & ${ }^{\star} 0401 /{ }^{\star} 11$ & $\mathrm{v} \beta 6$ & CD8+ & 14 & 12 & CAS SLTGTEHNEQF FGPG & $2 \mathrm{~S} 1$ \\
\hline
\end{tabular}

Ten V $\beta-C \beta$ amplification products displaying a dominant peak in the spectratype were subcloned and sequenced. The number of subclones sequenced from each sample is indicated. A minimum of three identical sequences was required to demonstrate the unequivocal presence of a clonal expansion. This criterion was satisfied in nine of 10 samples. The inferred amino acid sequence of the CDR3 loop is displayed in bold single letter amino acid code.

average of $11 \% \mathrm{CD} 8+$ cells, CD8- enriched samples consisted of at least $85 \%$ CD8+ cells, and CD8- depleted samples of less than $3 \%$ CD8+ cells (data not shown). The complexity of CD8+ and CD8- spectratypes, using this measure, was equivalent. The area under the peaks was approximately normally distributed, with a modal CDR3 length of $10(0.8)$ inferred amino acid residues. Comparison of spectratypes from unstimulated PBMC or PBMC stimulated for up to 12 days with PHA indicated no change in the repertoire detectable by this technique (results not shown).

The amplification efficiency of the panel of $22 \mathrm{~V} \beta-\mathrm{C} \beta$ primer pairs was $65 \%$ for $\mathrm{RA}$ patients and $76 \%$ for controls. Expansions were evident as dominant peaks against the background spectratype (fig 1) and the expansion frequencies, normalised for the amplification efficiency of each $V \beta$ family, are displayed in figure 2. RA patients displayed an expansion frequency at least $50 \%$ greater than in controls in families V $\beta 3,6,21$, and 24 in the CD8subset and $\mathrm{V} \beta 3,6,7,8,15,20,21$, and 23 in the CD8+ compartment. The CDR3 length of expansions ranged between 5 and 18 inferred amino acid residues with means of 10 for the control CD8- expansions, 11 for RA CD8expansions, and 10 for both control and RA CD8+ expansions. No association was evident between the number of expansions and the age of the person.

Table 2 displays the sequencing data from 10 expansions in six RA patients. A clonal expansion was demonstrated unequivocally in nine of 10 samples exhibiting dominant peaks. The use of J segments was non-random, with a preponderance for $\mathrm{BJ}^{\star} 2 \mathrm{~S} 1, \mathrm{BJ}^{\star} 2 \mathrm{~S} 3$, and $\mathrm{BJ}^{\star} 2 \mathrm{~S} 7$. Two control samples, without dominant peaks, revealed a variety of unique sequences.

\section{Discussion}

This spectratyping analysis of peripheral blood lymphocytes from RA patients and controls enables a qualitative assessment of the TCR $\beta$ repertoire across $22 \mathrm{~V} \beta$ families, covering $80-90 \%$ of the expressed TCR $\beta$ repertoire. Within a given $\mathrm{V} \beta$ spectratype, each peak represents the in-frame rearrangement of TCR $\beta$ genes with identical CDR3 length. Clonal T 
cell expansions can be detected against a polyclonal background with a sensitivity of approximately 1:1000 (results not shown). RA patients and controls had comparable numbers of CDR3 lengths per $\mathrm{V} \beta$ family (mean (SD) values $6.5(1.2)$ in controls and 6.0 (1.2) in $\mathrm{RA}$ ), indicating no macroscopic change in the peripheral blood TCR $\beta$ repertoire complexity in RA.

Dominant peaks were evident in several $\mathrm{V} \beta$ spectratypes, both in RA patients and controls. However, the frequency of expansions was significantly higher in RA patients than controls in both the CD8+ $(p=0.03)$ and CD8- $(p=0.02)$ subsets. The CD8 depleted samples consisted predominantly of CD4+ lymphocytes. However, clonal expansion within the CD4-CD8compartment cannot be excluded in this study and it is possible that this population includes high affinity autoreactive $T$ cells, which may be relevant in the pathogenesis of autoimmune disease. Sequencing of dominant peaks in this study revealed the presence of a clonal expansion in about $90 \%$ of cases. BJ segments ${ }^{\star} 2 \mathrm{~S} 1$, $\star 2 \mathrm{~S} 3$, and ${ }^{\star} 2 \mathrm{~S} 7$, encoding the motif $\mathrm{Q}(\mathrm{F} /$ Y)FGPG, were expressed preferentially, but their frequency was consistent with the nonrandom use of $\mathrm{BJ}$ segments previously reported in normal subjects. ${ }^{11}$

The biological significance of non-malignant peripheral blood expansions remains unclear. Initially CD8+ expansions were detected using monoclonal antibodies in elderly human subjects. ${ }^{12}$ These were thought to represent age related impairment of clonal regulation. While there is no correlation between frequency of expansions and age in this study, it remains possible that larger expansions develop in older subjects, and are detectable by less sensitive techniques. The majority of CD8+ expansions in normal and RA subjects have been shown also to express CD57. ${ }^{13}$ This phenotype has been associated with an MHC independent proliferative response to human fibroblasts infected with cytomegalovirus, ${ }^{14}$ but the significance of cytomegalovirus in the pathogenesis of RA remains controversial. ${ }^{15} 16$ The emergence of clonal expansions has been reported after antigenic stimulation, ${ }^{8}$ and the $\mathrm{CD} 45 \mathrm{RO}+$ phenotype of $\mathrm{CD} 4+^{3}$ and $\mathrm{CD} 8+{ }^{12}{ }^{17}$ expansions suggests a memory population. Surprisingly, expansions frequently appear to be CD28-, a phenotype thought to be associated with anergy. ${ }^{18}$ However, the CD4+CD28- expansions described previously in RA patients apparently retain the capacity to proliferate in response to TCR ligation. ${ }^{3}$

This study shows that clonal expansions are not merely the province of senescence and that microheterogeneity also exists in young subjects. The increased frequency of expansions evident in RA patients may reflect the proliferation of autoreactive clones, although the lack of CDR3 sequence conservation in the clones studied provides no evidence for a common autoantigen. Alternatively, peripheral blood expansions may reflect a pool of recently or repeatedly stimulated memory cells, recognising common pathogens, such as herpes viruses. Stimulation with interferon $\alpha$ has been shown to expand memory CD8+ cells in the absence of specific antigenic stimulation ${ }^{19}$ and proinflammatory cytokines in RA patients could result in the proliferation of certain memory cell populations. Finally, the finding that some unaffected relatives of RA display increased frequencies of expansions has prompted the suggestion that an underlying defect in $\mathrm{T}$ cell homeostasis predates and may predispose to disease. $^{2}$

We would like to thank the patients and controls who took part in this study and Ann Burrows for invaluable secretarial assistance. FCH was supported by the Medical Research Council. K T was supported by the Wellcome Trust.

1 Struyk L, Hawes GE, Chatila MK, Breedveld FC, Kurnick JT, van-den-Elsen PJ. T cell receptors in rheumatoid arthritis. Arthritis Rheum 1995;38:577-89.

2 Waase I, Kayser C, Carlson PJ, Goronzy JJ, Weyand CM. Oligoclonal T cell proliferation in patients with rheumatoid Oligoclonal cell proliferation in patients with rheumatoid
arthritis and their unaffected siblings. Arthritis Rheum 1996;39:904-13.

3 Schmidt D, Goronzy JJ, Weyand CM. CD4+ CD7- CD28$\mathrm{T}$ cells are expanded in rheumatoid arthritis and are characterized by autoreactivity. J Clin Invest 1996;97:2027-37.

4 Bowman SJ, Bhavnani M, Geddes GC, Corrigall V, Boylston AW, Panayi GS, et al. Large granular lymphocyte expansions in patients with Felty's syndrome: analysis using anti- $T$ cell receptor $V$ beta-specific monoclonal antibodies. Clin Exp Immunol 1995;101:18-24.

5 Hingorani R, Monteiro J, Pergolizzi R, Furie R, Chartash E, Gregersen PK. CDR3 length restriction of T-cell receptor beta chains in CD8+ T-cells of rheumatoid arthritis patients. Ann N Y Acad Sci 1995;756:179-82.

6 DerSimonian H, Sugita M, Glass DN, Maier AL, Weinblatt $\mathrm{ME}$, Rème $\mathrm{T}$, et al. Clonal V alpha $12.1+\mathrm{T}$ cell expansions in the peripheral blood of rheumatoid arthritis patients. J Exp Med 1993;177:1623-31.

7 Arnett FC, Edworthy SM, Bloch DA, McShane DJ, Fries JF, Cooper NS, et al. The American Rheumatism Association 1987 revised criteria for the classification of rheumatoid arthritis. Arthritis Rheum 1988;31:315-24.

8 Gregersen PK, Hingorani R, Monteiro J. Oligoclonality in the CD8+ T-cell population: analysis using a multiplex PCR assay for CDR3 length. Ann NY Acad Sci 1995;756: 19-27.

9 Rowen L, Koop BF, Hood L. The complete 685-kilobase DNA sequence of the human beta $T$ cell receptor locus. Science 1996;272:1755-62.

10 Reed PW, Davies JL, Copeman JB, Bennett ST, Palmer SM, Pritchard LE, et al. Chromosome-specific microsatellite sets for fluorescence-based, semi-automated genome mapping [see comments]. Nat Genet 1994;7:390-5.

11 Rosenberg WM, Moss PA, Bell JI. Variation in human T cell receptor $\mathrm{V}$ beta and J beta repertoire: analysis using anchor polymerase chain reaction. Eur J Immunol 1992;22:541-9.

12 Posnett DN, Sinha R, Kabak S, Russo C. Clonal populations of T cells in normal elderly humans: the T cell populations of T cells in normal elderly humans: the T cell equivalent to "benign monoclonal gammapathy" [pub-
lished erratum appears in J Exp Med 1994;179; 179:1077]. lished erratum appears in J Exp

13 Hingorani R, Monteiro J, Furie R, Chartash E, Navarrete C, Pergolizzi R, et al. Oligoclonality of V beta 3 TCR chains in the CD8+ $\mathrm{T}$ cell population of rheumatoid arthritis patients. J Immunol 1996;156:852-8.

14 Wang E C, Moss P A, Frodsham P, Lehner P J, Bell J I, Borysiewicz L K. CD8highCD57+ T lymphocytes in normal, healthy individuals are oligoclonal and respond to human cytomegalovirus. J Immunol 1995;155:5046-56.

15 Ferraro AS, Newkirk MM. Correlative studies of rheumatoid factors and anti-viral antibodies in patients with rheumatoid arthritis. Clin Exp Immunol 1993;92:425-31.

16 Tamm A, Ziegler T, Lautenschlager I, Nikkari S, Mottonen $\mathrm{T}$, Luukkainen R, et al. Detection of cytomegalovirus DNA in cells from synovial fluid and peripheral blood of patients with early rheumatoid arthritis. J Rheumatol 1993;20: 1489-93.

17 Hingorani R, Choi IH, Akolkar P, Gulwani-Akolkar B, Pergolizzi R, Silver J, et al. Clonal predominance of T cell
receptors within the CD8+ CD45RO+ subset in normal human subjects. J Immunol 1993;151:5762-9.

18 Linsley P, Ledbetter J. The role of the CD28 receptor during T cell responses to antigen. Annu Rev Immunol 1993; 11:191-212.

19 Tough DF, Borrow P, Sprent J. Induction of bystander T cell proliferation by viruses and type I interferon in vivo. Science 1996;272:1947. 